\title{
A FORMAÇÃO DO PROFESSOR DE HISTÓRIA E OS DESAFIOS CONTEMPORÂNEOS
}

\author{
HISTORY TEACHER TRAINING CONTEMPORARY AND CHALLENGES
}

\author{
Francisco Gleison da Costa Monteiro ${ }^{1}$ \\ Valdécio Sá Rocha²
}

\begin{abstract}
RESUMO: Neste artigo procuramos discutir os desafios da formação docente na sociedade contemporânea. O mote das discussões são as atividades de monitoria realizadas na disciplina de Metodologia do Ensino de História, na Universidade Federal do Piauí, Campus Senador Helvídio Nunes de Barros. O texto procura expor as estratégias que mobilizamos para a construção da identidade docente e em tempo apontar a monitoria como espaço dinâmico para ampliarmos a formação e articular a teoria à prática. Esta relação entre teoria e prática é fundamental para ratificarmos a identidade docente e reavaliarmos os espaços da prática e a produção do conhecimento historiográfico.
\end{abstract}

Palavras-chave: Monitoria. Identidade. Docência. Ensino de História.

\begin{abstract}
In this article we discuss the challenges of teacher education in contemporary society. The motto of the discussions are the monitoring activities in the discipline of History Teaching Methodology at the Federal University of Piauí, Campus Senator Helvídio Nunes de Barros. The text seeks to expose the strategies that mobilize for the construction of teacher identity and time point monitoring area as dynamic broaden the training and articulate the theory to practice. This relationship between theory and practice is key to ratify the teacher identity and re-evaluate the practice spaces and the production of historiographical knowledge.
\end{abstract}

Keywords: Monitoring. Identity. Teaching. History Teaching.

\footnotetext{
1 Doutorando em História pela Universidade Federal de Pernambuco. Professor de Metodologia de Ensino de História e Coordenador de Área do Subprojeto de História/PIBID, da Universidade Federal do Piauí/CSHNB.

2 Graduando em História pela Universidade Federal do Piauí/CSHNB.
} 


\section{A formação docente. Desafios contemporâneos}

Ninguém começa a ser educador numa certa terça-feira às quatro horas da tarde. Ninguém nasce educador ou marcado para ser educador. A gente se faz educador, a gente se forma, como educador, permanentemente, na prática e na reflexão sobre a prática.

Paulo Freire

Os pontos nodais deste artigo centram-se nas análises vivenciadas na ação do ensino/aprendizagem no âmbito do Programa de Monitoria ${ }^{3}$ em que procuramos vislumbrar é a relação entre professor e monitor para a construção da identidade do professor na prática docente.

Registra-se que todo semestre sempre procuramos solicitar monitores, pois pensamos que o Programa de Monitoria é um dos instrumentos viáveis para "(...) despertar nos alunos o interesse pela carreira docente e contribuir para a melhoria da qualidade do ensino de graduação" e, de fato, colaborar na formação dos futuros professores criando "condições para que os alunos possam desenvolver formas de pensamento e de comportamento ao trabalho científico independente, agindo como colaborador da produção acadêmica" (PIAUÍ/UFPI, 1999, p. 1).

A experiência foi realizada na disciplina de Metodologia do Ensino de História ${ }^{4}$ e procuramos dar ênfase aos momentos de planejamento, ação e diálogo com a teoria e a prática das discussões que cercam a formação da docência em atividades no âmbito da academia.

As experiências vivenciadas na relação professor/monitor nos proporcionaram momentos ímpares, pois nos ofereceram oportunidades para refletirmos sobre a prática docente, mas, principalmente, para avaliarmos e repensarmos as nossas (in)certezas na construção do conhecimento e da identidade docente.

Estes últimos são tidos como os principais desafios contemporâneos da docência. A ênfase está articulada pela ausência, nas licenciaturas, de discussões

3 O Programa de Monitoria da Universidade Federal do Piauí, regulamentado pela Resolução No 152/99/CEPEX, de 22/9/1999. É uma modalidade de ensino e aprendizagem coordenada no âmbito da Instituição pela Coordenadoria de Apoio e Assessoramento Pedagógico (CAAP), da Pró-Reitoria de Ensino de Graduação (PREG), desenvolvida por alunos regularmente matriculados nos cursos de graduação, bolsistas ou não bolsistas, que recebem orientação acadêmica dos professores, a fim de contribuir com a formação discente.

${ }^{4}$ As atividades foram desenvolvidas no Curso de História da Universidade Federal do Piauí do Campus Senador Helvidio Nunes de Barros-Picos. 
que projetem o futuro professor para relacionar teoria e prática. E não queremos aqui generalizar, pois existem experiências interessantes, mas ainda falta afinco na construção de debates plausíveis ao tema.

Doravante, a formação docente continua sendo o cerne dos cursos de licenciatura, e estas reflexões engendram-se, particularmente, nesta experiência, nas percepções existentes entre a distância do ensino de História na Universidade e de suas práticas na Educação Básica. No texto "Vivências na contramão" (1990), os historiadores Marco Antonio da Silva e Maria Antonieta M. Antonacci já nos apontavam as complexas relações que rondam o trabalho docente e os desafios que, coletivamente, ainda devemos enfrentar para mudar a História dita positivista.

Mediante este aspecto resta-nos questionar: por que estas vivências estão na contramão? Quais discursos estamos elaborando em nossas aulas? De ensino e pesquisa? De sociedade? Como os sujeitos são notados e problematizados na historiografia? Que relação estabelecemos entre Universidade e Escola?

Como vemos, a Universidade é, por excelência, um espaço dinâmico e propício para estes questionamentos, mas não é único. No entanto, essa dialética da construção do conhecimento histórico pauta-se, inicialmente, lá. E é exatamente no diálogo entre teoria e prática que as coisas vão acontecendo. É no diálogo entre professor e monitor que as (in)certezas são questionadas, a suspeição das obviedades são indiciadas e contraposta com as nossas inquietações ${ }^{5}$.

Unem-se a estas as descrenças da formação docente, que hoje é marcada pela descaracterização destes profissionais cuja ênfase medíocre é dada cotidianamente pela mídia. Articulados a elas estão os discursos dos governantes, que fingem não notar a importância de investimentos na área da educação. Mas estamos na luta, resistindo e não vamos sucumbir a estes discursos nefastos.

Partindo-se deste raciocínio, percebemos que o desafio para a formação docente é enfrentar a realidade e confrontá-la com as nossas práticas. No dizer de Milton Santos, "O trabalho do professor é arriscado. Quem teme perigos deve

\footnotetext{
${ }^{5}$ Estas questões também são interpretadas e discutidas nas reuniões, pedagógicas e administrativas, que realizamos com os alunos do Programa Institucional de Bolsa de Iniciação Docência/PIBID. Ainda ampliamos os debates relativos às atividades docentes cursadas nos Estágios Obrigatórios I, II, II, IV, compreendendo 405 horas de prática.
} 
renunciar à tarefa do ensino. E se quiser ser ao mesmo tempo professor intelectual, está fadado a correr riscos ainda maiores". (SANTOS, 1998, p. 09)

Incentivados pelos apontamentos de Santos, estamos procurando avançar e criar estratégias para romper com estes percalços, e a monitoria centra-se como uma perspectiva para desconstruir o dissabor da docência, enquanto construímonos como profissionais e planejarmos caminhos possíveis para equiparar às distâncias entre Universidade e Escola.

Quando focamos as análises para a formação docente, referimo-nos ao desenvolvimento de estratégias que oportunizem espaços para a efetivação das habilidades que definem a docência. Essa formação específica e, ao mesmo tempo, holística pode ser a condição, proporcionada pelos diálogos entre professor e monitor, do disciplinamento nos estudos e da articulação reflexiva pela teoria/prática.

Partindo desses pressupostos é que fomos planejando ações e compartilhando-as com os sujeitos envolvidos no processo de ensino/aprendizagem: professor-monitor-discentes. Primeiramente, procuramos relacionar o planejamento das atividades de monitoria com o Plano de Curso da disciplina de Metodologia do Ensino de História e essa ação possibilitou ao alunomonitor a manusear e produzir materiais didáticos e pô-los em prática, permitindoo uma formação contínua e reflexiva da prática docente e dos materiais utilizados pelo professor.

Além desse direcionamento, procuramos incentivar o aluno-monitor na formação de grupos de estudos, na realização de oficinas pedagógicas e de orientações individualizadas e grupais que foram realizadas no contraturno.

Desta forma avaliamos que permitimos ao aluno-monitor a participação no conjunto de atividades didático-pedagógicas da disciplina, contribuindo para o futuro exercício do magistério e a capacitá-lo para a reflexão crítica sobre a elaboração de planos de ação e da seleção de materiais didáticos que permitisse aos discentes várias possibilidades para a produção do conhecimento historiográfico.

Para tanto, as questões postuladas acima nos possibilitaram planejar conjuntamente e reavaliar algumas atividades, mas também nos aproximou dos 
discentes e nos levou a notá-los como sujeitos dinâmicos por um lado, mas passivos por outros.

Este último, da passividade, nos intrigou em algumas ocasiões das atividades e fomos cercando as acepções e/ou aversões que tinham os discentes nos momentos de verbalização dos conteúdos, da realização das atividades práticas e das orientações individuais/grupais. Registra-se, por exemplo, que estes direcionamentos dialógicos proporcionaram discussões densas nos encontros de orientações, favorecendo a intervenção nas leituras teóricas, nos métodos selecionados para abordar o ensino de História, na interpretação da noção de tempo e do sujeito na História, das análises técnicas e estéticas dos trabalhos produzidos.

Estas condições de intervenção se foram permeando nas orientações e tomadas como eventos importantes para avaliarmos o processo ensinoaprendizagem que se estava construído no âmbito da monitoria, pois foi preciso que o monitor percebesse que estava inserido num processo complexo e que desempenhava uma função importante ao lado do professor, pois coordenava, intervinha, questionava a suspeição das obviedades na docência. Logo, o monitor podia ver-se, na prática, notado como sujeito, pois atuava de modo técnico e esquemático na vida acadêmica e em meio às discussões teóricas levadas à prática, teve a oportunidade de observar mais de perto os questionamentos e inquietações em torno do ensino de História.

Articulando estas questões com o da historiadora Déa Ribeiro Fenelon, podemos notar que o diálogo com os alunos, adverte-nos, é necessário para que possamos questionar a formação que Ihes oferecemos e os instrumentos didáticos postos para nós de forma arbitrária. Para a autora, precisamos assumir papéis nada convencionais frente às práticas docentes atuais, seja na interpretação que fazemos da História e da sociedade ou das diversas estratégias que tecemos para ampliar o conceito de História e sua prática, pois estes se encontram limitados nos programas oficiais de educação. Daí, "temos de nos considerar como 'produtores' nesta sociedade que queremos democrática e não como simples repetidores e reprodutores de concepções ultrapassadas" (FENELON, 2008, p. 24).

Ao indagar sobre o profissional de História que formamos, Déa Fenelon nos dá a dimensão do problema, que perpassa a concepção de ciência que temos hoje, 
o que nos remete também à realidade social em que se exprimiu tal conceito. Desse modo, temos uma disciplina, de certo modo, rotulada, hierarquizada e limitada em seu objeto de estudo, que seria o passado e que nos remete a articulála à ciência dissociada do social em que

O conhecimento é visto como algo passivo, despolitizado e sempre intelectualizado, e a História que se produz dentro destes limites institucionais com esta perspectiva, não consegue mais do que formar profissionais que serão os reprodutores destas concepções, perspectivas, informações, saber, etc. (FENELON, 2008, p. 26).

Com isso, a autora nos adverte para o fato de que o fazer História não pode estar dissociado da prática, pois assim estaríamos apenas reproduzindo conhecimentos vagos, fragmentados, sem problematizar o ensino e a pesquisa e a capacidade que tem os alunos de também questionar a ordem e subvertê-la. Por isso a importância da formação docente a partir da monitoria, por isso iniciarmos ai a reflexão sobre o tipo de História que estamos transmitindo aos nossos alunos, pois, segundo a autora, não é difícil reconhecer esses efeitos, quando os resultados aparecem. Portanto,

O que é preciso distinguir, mas também concretizar é que não se trata de simplesmente reconstituir o empírico. O trabalho do historiador comporta sim um trabalho que não pode e nem deve ser superficial ou de segunda mão, mas uma verdadeira penetração direta na matéria histórica. (FENELON, 2008, p. 34).

Com isso, podemos constatar que a História, da forma como é ensinada, apresenta-se como algo pronto e acabado, impõe verdades e, à medida que é rotulada como um estudo do passado, passa a impressão de algo dispensável para os alunos, que constantemente se perguntam o porquê de estudar História.

Quanto a isso cabe ao professor refletir sobre o momento vivido e unir a teoria à prática, para buscar desconstruir esses rótulos, mas, para tanto, deve contornar estes obstáculos presentes no ensino de História, devendo recorrer à sua intelectualidade e formação ativa, para que não venha a reforçar mais ainda essa situação de superficialidade da disciplina de História. Para avançarmos avaliarmos a necessidade de trabalhamos com outros referenciais complementares para além 
dos livros didáticos e que outras linguagens ${ }^{6}$ possam nos auxiliar, metodologicamente, para aproximar os conteúdos da realidade dos alunos.

\section{Planejando a formação docente}

O planejamento, na monitoria, nos habilitou a analisar as dimensões teóricometodológicas do professor de História, uma vez que fora socializado pelo professor ao monitor a elaboração dos materiais didáticos, as problemáticas do ensino de História, as implicações epistemológicas e relação destas com a produção do conhecimento e o uso dos instrumentos didáticos. Nas reuniões de orientação - professor/monitor - foram discutidos os seguintes pontos:

1. Projeto de Monitoria;

2. Plano de aula;

3. Os processos avaliativos;

4. Orientações (individuais e grupais).

Esta conjunção de atitudes possibilitou tanto ao professor como ao monitor terem uma visão holística em torno das atividades a serem desenvolvidas e, sobretudo, oportunizar a efetivação da orientação aos alunos. Essa ação deslocou o monitor da condição de orientado para a de orientador, o que exigiu competência intelectual e metodológica, que foram adquiridas ao longo do curso. Dessa forma, os planejamentos de ação nos possibilitaram identificar os pontos nos quais precisaríamos melhorar, e a auto-avaliação ponderou como importante o diálogo mantido entre professor e monitor e, posteriormente, entre monitor e alunos.

Reunimo-nos em sala de aula e, coletivamente, fomos expondo o trajeto dos trabalhos e da inserção de todos nas atividades. Este espaço priorizou direcionamentos para o planejamento metodológico. Nesse ritmo, o diálogo com

6 Consideramos como linguagens o uso que os professores fazem de materiais diversos que transformados em instrumentos didáticos rompem com estrutura "tradicional" e linear do livro didático. Então, compreendemos que essas linguagens sejam as pinturas, jornais, charges, músicas, mapas, literatura de cordel e outros que considerem pertinentes para sensibilizar os alunos a interpretarem a História e a articularem as relações do tempo passado e do presente. 
os alunos tornou-se possível e, através da monitoria, foram explicitadas as ações cujo respaldado encontrava-se no plano de aula e no projeto de monitoria.

Ao passo que se realizavam as atividades, o monitor buscava observar meios de como poderia se adaptar aos tempos pedagógicos e às indagações dos alunos. Estas foram permeadas por questões que iam desde aquelas relacionadas à metodologia até a insegurança com o tema tratado, mas as experiências teóricas vivenciadas pelo monitor em disciplinas anteriores e nos debates atuais sucumbiram, em alguns momentos, as instabilidades nas orientações do monitor para com os alunos.

Durante as orientações extraclasses, era imprescindível discutir, nas reuniões técnicas, que o monitor demonstrasse segurança e domínio sobre os temas abordados, mas, quando os momentos instáveis da teoria fossem insistentes, deveria o monitor procurar o professor-orientador, para juntos criarem estratégias e atuarem perseverantemente nas articulações entre ensino e pesquisa.

Estes reforços se consolidavam na medida em que o compromisso com a prática se estabelecia de forma planejada. Neste momento notava-se que a interação e a aprendizagem tinham sido proveitosas para orientador-monitoralunos, levando-os, segundo Pimenta, "a investigar a própria atividade para, a partir dela, constituírem e transformarem os seus saberes-fazeres docentes, num processo contínuo de construção de suas identidades como professores" (1999, p. 18).

Ressaltamos que ambos tinham liberdade de criar, motivar e intervir nas práticas planejadas, pois a condução para a pesquisa não podia ser interpretada como algo fechado e alheio aos processos individuais e às realidades dos alunos. Portanto, as dificuldades que os alunos relatavam ao monitor foram sanadas com base no que estes compreendiam e absorviam do diálogo monitor/alunos. Para tanto, a atenção que dedicaram às orientações com o monitor tiveram reflexos importantes para a maturidade intelectual e trocas de experiências que foram adquiridas em outras disciplinas: Estágio Obrigatório, Didática e Avaliação da Aprendizagem.

Avaliamos ainda que precisamos avançar em direção a um planejamento interdisciplinar, para que possamos absorver as experiências múltiplas, pois 
precisamos uni-las, para fortalecermos a prática e mobilizá-las para a dinamização da formação do futuro professor.

\section{A prática docente na produção de materiais didáticos}

As estruturas pedagógicas que temos nas escolas ainda sustentam que a aprendizagem dos alunos deve partir de um currículo fechado e matizado por parâmetros. Mas a quem interessa esta estrutura? O que dizem os manuais? Como os professores avaliam esse processo?

Pensar o ensino de História implica problematizar os instrumentos didáticos e os currículos, pois ambos intervêm na prática da docência e na produção do conhecimento historiográfico. Portanto, são saberes matizados que, segundo Renilson Rosa Ribeiro, nos revelam aspectos ideologizantes, pois "esse conhecimento, [...] não pode apenas ser analisado como algo estático e naturalizado como um conjunto de informações e materiais para ser absorvido por professores e alunos de maneira passiva". (RIBEIRO, 2004, p. 02).

A crítica do autor refere-se ao fato de que os currículos produzem discursos que constroem e formam modelos tanto de professores, quanto de alunos; ou ainda de escolas e condutas. Com isso, Renilson Ribeiro destaca que o currículo não é apenas um meio de representar o sujeito, pois ele acaba por construí-lo, produzindo assim identidades determinadas. É preciso, portanto, que nos voltemos para quem produz esses conhecimentos. Ribeiro (2004) nos lembra, ainda, que esses autores constroem discursos que estão vinculados aos lugares de produção e política cultural de onde falam.

Portanto, ponderamos a necessidade de criar estratégias de abordagens, para exercitarmos a atividade de pensar as relações entre cultura e currículo (MACEDO, 2006, p. 105), em que os professores e alunos apareçam como sujeitos da produção do conhecimento.

Partindo dessa perspectiva, avaliaremos agora as atividades práticas que rumaram para tencionar o currículo e o espaço da escola como produção cultural. Portanto, os alunos de Metodologia do Ensino de História foram sensibilizados a 
produzir materiais didáticos cujas análises articulassem a História local e cultural. Muitos temas vieram à tona, vejamos:

- História e cidade;

- Os vaqueiros do da região Centro-Sul do Piauí;

- As imagens portuguesas de santos católicos no período imperial;

- Os produtores de alho nas margens do rio Guaribas;

- A produção de mel de abelha e a geração de emprego e renda;

- As transformações urbanas na cidade e os espaços de lazeres.

Após a apresentação da atividade, os alunos, divididos em grupos, foram orientados pelos vieses teórico-metodológicos da pesquisa. Portanto, tinham a liberdade de escolherem a temática, mas tinham que inseri-la em um roteiro que fora anexado ao programa da disciplina que normatizava a estrutura da escrita de um capítulo de livro didático.

O objetivo dessa atividade foi provocar nos alunos de graduação a criatividade e o desenvolvimento de habilidades para produção de materiais didáticos e fazêlos notar que o futuro professor precisa se afirmar diante dos instrumentais que são impostos aos professores da educação básica, pois este deve ser um intelectual autônomo, capaz de construir sua identidade, como professor e intelectual da História, alicerçado em seus princípios e com base na confiança de sua formação que o capacitou para isso. É nesse aspecto que questionamos as práticas, que nos movimentamos e praticamos ensaios e construímos conexões com a ação docente (TARDIF, 2010).

A formação do professor, portanto, é fundamental para que esses pontos sejam enxergados e debatidos em proveito de um ensino de História, que queremos crítico e combativo, mas é preciso que olhemos para a prática docente em sala de aula, como faz Christiane Burkert Teixeira, em seu estudo, que se volta para os saberes que os professores desenvolvem e tomam a sala de aula como um laboratório.

Para tanto, a autora observa as tendências contemporâneas na formação de professores, que são baseadas 
Na formação de um profissional prático-reflexivo, capaz de autodesenvolvimento numa perspectiva crítico-reflexiva. Um profissional capaz de relativizar seus saberes, questionando-os em busca de novos saberes, que também serão relativizados, questionados, refletidos, analisados, numa busca incessante por saberes revestidos de episteme. (TEIXEIRA, 2004, p. 01).

Destarte, tudo nos leva a refletir sobre como a identidade do professor é contínua e complexa e se constrói nas práticas que estabelece no cotidiano do trabalho docente, nos leva também a crer que é necessário socializarmos estes saberes docentes e dar-Ihes a devida importância que lhe é conferida (ou que deveria ser).

Em se tratando da formação do professor, é importante perceber a oposição à racionalidade técnica, pois para Teixeira (2004), podemos compreender a identidade docente como a indissociabilidade entre a identidade pessoal e profissional do professor. Portanto, o professor como um profissional que está em contínua formação, tende a uma constante reflexão sobre suas práticas. Sendo assim, seu cotidiano é de grande importância para sua formação profissional, pois a pessoa não se dissocia do profissional, mas o complementa e o ajuda em suas práticas e desenvolvimento intelectual. Para Teixeira essa tendência contemporânea

\footnotetext{
Deve estar centrada na formação de profissionais aptos a intervirem de forma competente em diversas situações, capacidade está caracterizada pela associação do coerente, do caráter cognitivo e afetivo, explicativo e normativo, de conhecimentos, capacidades, teorias, crenças e atitudes críticas e reflexivas, compreendendo a formação de um profissional competente com capacidade de autodesenvolvimento reflexivo. (TEIXEIRA, 2004, p. 06).
}

Estas diversas situações nos levam a ratificar a necessidade de ampliarmos, na graduação em História, a articulação entre teoria e prática, e estas podem ser efetivadas nos espaços da monitoria, da prática como componente curricular, do PIBID - Programa Institucional de Bolsas de Iniciação à Docência, dos Estágios Obrigatórios, dos Projetos de Extensão. Estes espaços oportunizam ao futuro professor acompanhar seu desenvolvimento de forma crítica e reflexiva, tendo assim um constante aproveitamento e ressignificação de sua identidade e competências como professor. 
Voltemos agora a falar sobre as atividades de pesquisa moldadas na estrutura de livro didático. Pois bem, o centro desta atividade, conforme havíamos enfatizado antes, é a prática estabelecida a partir da produção de materiais didáticos cujo destino das produções era os alunos do Ensino Fundamental II ( $8^{\circ}$ e 90 anos).

Os desafios enfrentados pelos alunos foram técnicos e teórico-metodológicos, pois tiveram que lidar com uma série de elementos para a construção da problemática da pesquisa e também da estruturação do capítulo, por exemplo: tipo de letras, tamanho, enredos textuais, caixa de textos, uso de imagens (fotografias, pinturas, etc.), mapas e sugestões de atividades.

Definidos os eixos de atuação de cada grupo, foi montado um agendamento de orientações que percorriam os ritmos da pesquisa, da coleta de dados e a construção dos textos. Nesse ínterim, logicamente, os diálogos permaneceram sólidos entre professor-monitor-alunos.

No entanto, os ritmos do contato entre monitor-alunos são definidores da construção da prática e da identidade do professor, pois ajuda-nos a iniciar o enfrentamento a um sistema de ensino que se encontra engendrado nos moldes do capitalismo e que prejudica seriamente o ensino de História. Esta perspectiva, articulada à do historiador catalão, Josep Fontana, nos induz a levar monitor e alunos "a tomar consciência das dimensões sociais do mundo em que vivem, e pelo que me consta o que é feito por estes é de um valor inestimável". (FONTANA, 1998, p. 34).

Portanto, é imprescindível que conheçamos os materiais didáticos com perspicácia, pois estes nos ajudarão a descontruir ideologias ou simplesmente ratificá-las. Talvez, melhor que conhecermos seja exercitarmos a sua produção e confrontá-los com os manuais oficiais, pois, ao pontuarmos as tensões existentes entre as memórias e as diversidades culturais, notaremos que os heróis ainda continuam estáticos e que os movimentos sociais não fazem parte dos materiais didáticos e dos discursos dos professores.

Reforçamos que as atividades buscaram a autonomia da produção intelectual do acadêmico, para que, através das intervenções e monitoração dos processos e construção dos materiais, possam ser identificadas formas de atuação e a busca por um ensino de História, que não se mostra satisfatório e distancia-se de um 
pensamento crítico e reflexivo. Daí a possibilidade de centrarmos a produção dos capítulos na História local, pois devemos buscar outros sujeitos na História e, a partir dessa mudança interpretativa, exercitar os alunos a notarem que a História é uma ciência sempre em movimento.

Para nos auxiliar nessa produção, recorremos às análises sempre atuais e motivadoras de Kazumi Munakata, pois nos mostra que "O ideológico do livro didático se encontra para além dos eventuais lapsos conceituais e éticos que possa conter; ele lhe é estruturante, na medida em que esse material é um dos dispositivos fundamentais da educação escolar" (MUNAKATA, 2007, p.137). O autor ainda nos lembra da dimensão dos parâmetros avaliativos e ideológicos que rondam os livros didáticos e nos faz refletir sobre seus manuseios e abordagens. Uma tarefa nada fácil, mas que requer um direcionamento planejado e hábil do professor que se dispôs a interditar o óbvio e a mover-se pelas contradições que figuram tacitamente os conteúdos escolares. Para tanto, enfatiza Munakata,

\footnotetext{
O que se postula, então, é não a oposição entre o professor e o livro didático, e sim, ao contrário, a escolha, pelo professor bem formado, de livros adequados às diferentes necessidades e expectativas. Um e outro aparecem como aliados na luta contra a rigidez do currículo, cristalizando exatamente no livro didático. Aposta-se então em um novo livro didático, adotado por um novo professor? (MUNAKATA, 2007, p.141).
}

Portanto, caberá ao professor indagar o livro didático, propor situações lógicas para que os alunos, direcionados pelo professor, construam sequências problematizadoras (ROCHA, 2004). No entanto, requer do professor habilidades que o mesmo deverá ter exercitado no momento da formação e ampliará na prática docente, pois sua percepção será fundamental para detectar as limitações, externas e internas, que surgirão nos conteúdos estruturantes dos livros didáticos (ROCHA; REZNIK \& MAGALHÃES, 2009).

Percebemos com a análise do autor que o livro é apenas um elemento dentro do processo de ensino-aprendizagem, e, como tal, os seus efeitos dentro do ensino de História, independentemente de serem negativos ou positivos, não irão depender exclusivamente de seu conteúdo, pois precisamos lembrar também, do modo como este conteúdo é abordado, analisado e tensionado por professores e alunos. 
Com isso notamos a importância de se estudar o processo de formação de professores aliado ao estudo dos seus instrumentos e espaços de produção, pois tudo isso forma o contexto no qual irá se desenvolver o profissional em História. Ao discutirmos sobre os instrumentos de trabalho do professor de História não podemos nos limitar apenas ao livro didático, pois existem outros meios que podem dinamizar as aulas, e essa discussão não ficou de fora dos nossos debates.

Quem nos auxiliou nessa discussão foi Francisco Régis Lopes Ramos, ao trabalhar o uso de objetos em aulas de História, acompanhada por uma reflexão sobre a sociedade de consumo. Para tanto, a discussão nos leva ao caráter acelerado da sociedade de consumo e seus objetos descartáveis, o que dificulta até mesmo o desenvolvimento de uma relação com esses objetos. Segundo Ramos,

Enfrentar a sociedade de consumo é, ou deveria ser, o pressuposto básico de qualquer atividade relacionada ao uso de objetos em aulas de história, pois a consciência histórica não trata do passado isolado e sim das várias tramas entre pretérito e presente, sem esquecer do campo de expectativas ligado ao futuro. (RAMOS, 2008, p. 181).

Essa sociedade veloz, repleta de objetos que se desgastam rapidamente, certamente não estaria contribuindo com o uso desses objetos no ensino de História, prontamente o autor fala em "enfrentamento", já que "o conhecimento histórico se faz no presente e pelo presente que interpreta o passado" (RAMOS, 2008, P. 181). Logo nos vemos perdidos no que o autor chama de "tempo dos objetos" situado numa sociedade de consumo que acaba por afetar o caráter educativo dos museus, como exemplifica Ramos.

Desse modo, esse processo, ao mesmo tempo em que se torna impedimento, também pode ser estudado nas condições de sua formação e imposição sobre o contexto social em que se encontra. Assim, "os tempos de duração dos artefatos contemporâneos podem ser, por exemplo, um campo fértil para a composição de problemas históricos nas aulas de história" (RAMOS, 2008, p.188).

Com isso é preciso que o professor saiba ler objetos e dotá-los de instrumentos problematizadores: quem produz estes objetos? Por quê? Que uso faz a sociedade destes? Qual o contexto e o propósito de sua produção? Quais tempos de produção e uso destes objetos? Estas indagações podem sensibilizar alunos da educação básica a entenderem a dinâmica das relações sociais que nos 
cercam e que não são neutras, mas para as quais precisamos construir uma crítica de suas formações, objetivas e subjetivas.

Sendo assim, cabe ao professor selecionar fontes, objetos e outras ferramentas que problematizem as relações sociais e tornar dinâmicas as aulas de História, despertando nos alunos a capacidade de interpretação da realidade, pois além de ler o livro e interpretá-lo, os alunos devem também exercitar o ato da pesquisa, da observação e da interação com o meio em que estamos inseridos.

Portanto, o resultado da produção de materiais didáticos pelos alunos de Metodologia do Ensino de História primou pelo exercício da autonomia intelectual, da ampliação do ensino de História, como estratégia para rever programas oficiais e tencioná-los, rumo à transformação dos alunos em sujeitos pensantes e dinâmicos.

\section{Tempo de esperança... Uma necessidade ontológica}

A formação docente tem ganhado dimensões pelo Brasil e várias experiências têm ampliado as discussões acerca da teoria e metodologia na área do Ensino de História. Pelas noções e entusiasmo que temos acompanhado, nos comovemos a revermos práticas e a aproximação com Paulo Freire, no livro "A Pedagogia da Esperança: um reencontro com a Pedagogia do Oprimido", que nos parece o caminho seguro para construirmos possibilidades de interpretação para a identidade docente.

A insistência de construirmos possibilidades de ampliarmos o trabalho docente está na ânsia em notar a docência como uma alquimia que forma e transforma, que une e fragmenta, que atrai e retrai os diversos protagonistas que dela se aproximam e tornam-se sujeitos.

A importância dessas experiências pôde ser percebida ao longo do processo, nas atividades realizadas e discussões promovidas pelo professor-monitor-alunos. Os desafios enfrentados, sempre com condescendência, nos direcionaram para superar o ensino que temos na prática, mas nunca separá-la da teoria. Eis aí uma esperança. Para avançar e dizer que estamos no caminho certo. Segundo Freire, "A esperança é uma necessidade ontológica" (1997, p. 05). 
Precisamos nos renovar constantemente e, para que não sejamos submissos aos programas oficiais, se faz necessário que estejamos atentos às nossas abordagens, se estas realmente atendem ao que fomos orientados e "treinados" a promover. Ou será que estamos apenas reforçando o ensino indesejável, irreal e retrógrado? Cremos que este não seja o nosso trajeto, pois, acreditamos em mudanças, mesmo que o processo seja lento. Vale a pena a abnegação, mas não utopias passíveis de abandono. Merecem, portanto, serem empreendidas e incentivadas por todos nós ações esperançosas. No entanto, devemos agir não somente nas abstrações, mas na concretude das cousas. Nas palavras de Paulo Freire,

\begin{abstract}
Não quero dizer, porém, que, porque esperançoso, atribuo á minha esperança o poder de transformar a realidade e, assim convencido, parto para o embate sem levar em consideração os dados concretos, materiais, afirmando que minha esperança basta. Minha esperança é necessária, mas não é suficiente. Ela, só, não ganha luta, mas sem ela a luta fraqueja e titubeia. Precisamos da herança crítica, como o peixe necessita de água despoluída (FREIRE, 1997, p. 05).
\end{abstract}

As transformações acontecem, mas temos que agir e perscrutar.

\title{
Referências
}

BRASIL. Conselho Nacional de Educação. Parecer CNE/CES n. 1363/2001.

Retificação do Parecer CNE/CES 492/2001, que trata da aprovação das Diretrizes Curriculares Nacionais dos Cursos de Filosofia, História, Geografia, Serviço Social, Comunicação Social, Ciências Sociais, Letras, Biblioteconomia, Arquivologia e Museologia. Brasília, 12 de dezembro de 2001.

BRASIL. Conselho Nacional de Educação. Resolução CNE/CP n. 01/2002. Institui Diretrizes Curriculares Nacionais para a Formação de Professores da Educação Básica, em nível superior, curso de licenciatura, de graduação plena. Brasília, 18 de fevereiro de 2002.

FENELON, D. R. A formação do Profissional de História e a realidade do ensino. Tempos Históricos. v. 12, $1^{\circ}$ semestre de 2008, p 23-35.

FONTANA, J. História depois do fim da História. Bauru, SP: EDUSC, 1998. (Coleção Essência)

FREIRE, P. A Educação na Cidade. São Paulo: Cortez, 1991. 
MACEDO, El. Currículo: Política, Cultura e Poder. Currículo sem Fronteiras, v. 6, n. 2, pp.98-113, Jul/Dez 2006.

MONTEIRO, F. G. da C. M. História e Memória em Álbuns de Famílias. In.: ARAÚJO, J. S. de; LIMA, F. O. A. (Org.) História: entre fontes, metodologias e pesquisa. Teresina, PI: EDUFPI; Imperatriz, MA: Ética, 2011.

MUNAKATA, K. O livro didático e o professor: entre a ortodoxia e a apropriação. In. MONTEIRO, A. M. da C. GASPARELLO, A. M. MAGALHÃES, M. S. (Org.). Ensino de História: sujeitos, saberes e práticas. Rio de Janeiro: Mauad X: FAPERJ, 2007.

PIAUÍ. Conselho de Ensino Pesquisa e Extensão da UFPI. Resolução no 152/99, de 09 de setembro de 1999.

PIAUÍ. UNIVERSIDADE FEDERAL DO PIAUÍ. Curso de História. Projeto Pedagógico do Curso de Graduação em História. Picos, 2007.

PIMENTA, S. G. (rg.). Formação de professores: identidade e saberes da docência. 2. ed. São Paulo: Cortez, 1999.

RAMOS, F. R. L. A insustentável leveza do tempo: os objetos da sociedade de consumo em aulas de história. Educação em Revista. Belo Horizonte. n. 47, jun. 2008, p.179-196.

RIBEIRO, R. R. O saber (histórico) em parâmetros: O ensino da História e as reformas curriculares das últimas décadas do século XX. Mneme. Revista virtual de humanidades. n. 10, v. 5, abr./jun.2004. Disponível em: http://www.periodicos.ufrn.br/mneme/article/view/196. Acesso em: 12 jan. 2015.

ROCHA, H. A. B. A escrita como condição para o ensino e aprendizagem de história. Revista Brasileira de História. São Paulo, v. 30, n. 60, 2010, p. 121-142.

Por uma aula de história problematizadora. XII Encontro Nacional de Didática e Prática de Ensino. XII ENDIPE Conhecimento Local e Conhecimento Universal. Curitiba: Puc PR, 2004.

; REZNIK, L.; MAGALHÃES, M. de S. A história na escola: autores, livros

e leitores. Rio de Janeiro; Editora FVJ, 2009.

SANTOS, M. O professor como intelectual na sociedade contemporânea. Conferência pronunciada na abertura do IX Encontro Nacional de Didática e Prática de Ensino, realizado em Águas de Lindóia-SP. De 4 a 8 de maio de 1998.

SCHMIDT, M. A.; BARCA, Isabel (Org.). Aprender História: perspectivas da educação histórica. v. 3, Ijuí: Ed. Unijuí, 2009. (Coleção cultura, escola e ensino). 
SILVA, M. A. da; ANTONACCI, M. A. M. Vivências na contramão: Produção de saber Histórico e Processo de Trabalho na Escola de $1^{\circ}$ e $2 \circ$ Graus. Revista Brasileira de História. São Paulo. v. 9, n. 19, pp. 9-29, set. 89/fev. 90.

TARDIF, M. Saberes docentes e formação do profissional. 2. ed. Rio de Janeiro: Vozes, 2002.

TEIXEIRA, C. B. Ressignificação da identidade do professor na formação docente. Revista Eletrônica de Ciências da Educação. Paraná, v. 3, n. 1, 2004. Disponível em: <http://revistas.facecla.com.br/>. Acesso em: 21 de mar. 2012.

Recebido em 03 de março de 2015 Aprovado em 12 de novembro de 2015 